\title{
Correction: Impact of energy turnover on the regulation of glucose homeostasis in healthy subjects
}

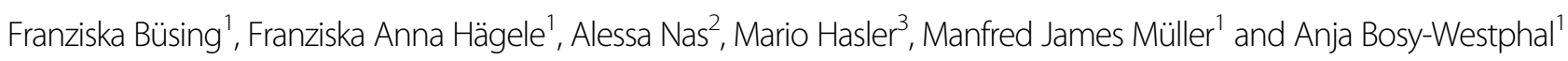

\section{Correction to: Nutrition \& Diabetes \\ https://doi.org/10.1038/s41387-019-0089-6 \\ published online 08 August 2019}

Since publication of this article the authors noted that the legend for Table 1 was incomplete, as the subtitle was missing. The complete table should appear as given below:
This has been corrected in both the PDF and HTML versions of the Article.

Published online: 07 October 2019 


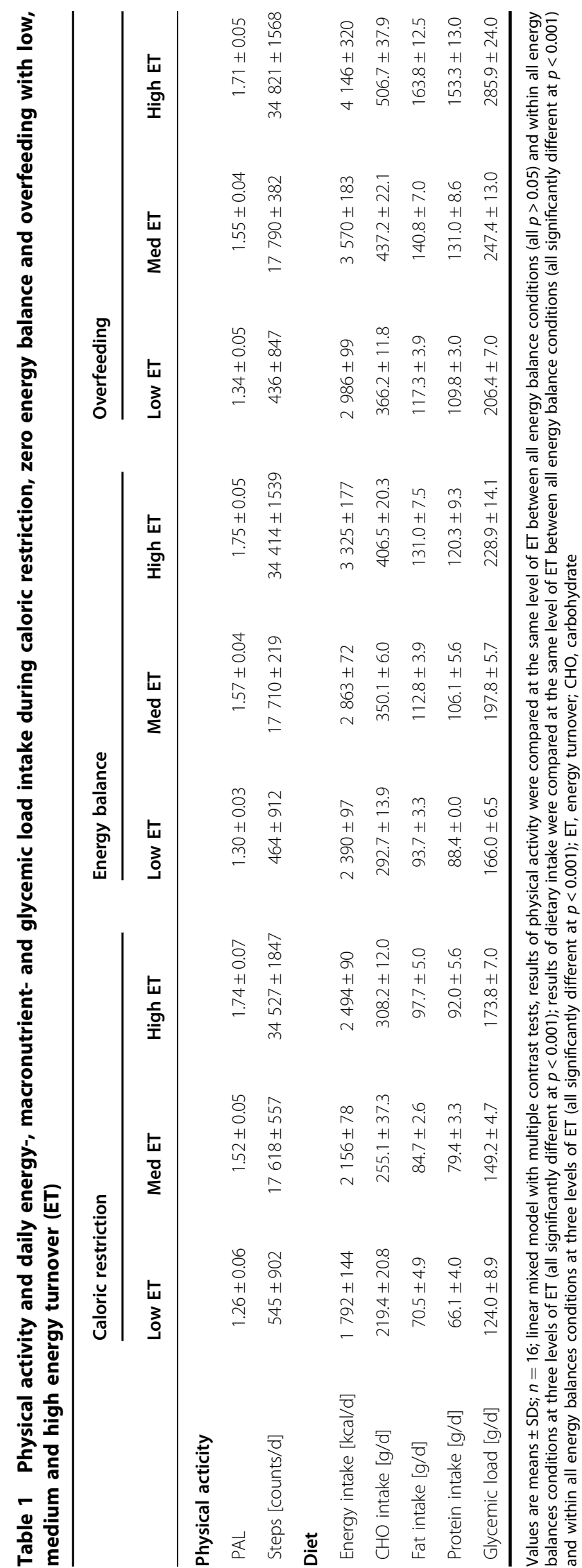

